\title{
Orai3 calcium channel and resistance to chemotherapy in breast cancer cells: the p53 connection
}

\author{
Jessy Hasna ${ }^{1}$ - Frédéric Hague ${ }^{1} \cdot$ Lise Rodat-Despoix $^{1} \cdot$ Dirk Geerts $^{2} \cdot$ Catherine Leroy $^{3} \cdot$ David Tulasne $^{3}$. \\ Halima Ouadid-Ahidouch ${ }^{1} \cdot$ Philippe Kischel $^{1}$
}

Received: 9 September 2016 / Revised: 23 September 2017 / Accepted: 25 September 2017 / Published online: 11 January 2018

(c) ADMC Associazione Differenziamento e Morte Cellulare 2018

\begin{abstract}
Orai proteins are highly selective calcium channels playing an important role in calcium entry. Orai3 channels are overexpressed in breast cancer (BC) tissues, and involved in their proliferation, cell cycle progression and survival. Herein, we sought to address the involvement of Orai3 in resistance to chemotherapeutic drugs. Using high-throughput approaches, we investigated major changes induced by Orai3 overexpression, including downstream signaling mechanisms involved in BC chemotherapy resistance. Resistance was dependent on external calcium presence and thus Orai3 functionality. This effect allowed a downregulation of the p53 tumor suppressor protein expression via the pro-survival PI3K/Sgk-1/Sek-1 pathway. We demonstrated that 553 degradation occurred not only via Mdm2, but also via another unexpected E3 ubiquitin ligase, Nedd4-2. We found supporting bioinformatic evidence linking Orai3 overexpression and chemoresistance in large human BC data sets. Altogether, our results shed light on the molecular mechanisms activated in BC cells commonly found to overexpress Orai3, allowing resistance to chemotherapeutic drugs.
\end{abstract}

\section{Introduction}

Cancer cells have the ability to become resistant to a variety of drugs, and resistance of cancer cells is therefore a major

Edited by M. Oren

Halima Ouadid-Ahidouch and Philippe Kischel contributed equally to this work.

Electronic supplementary material The online version of this article (https://doi.org/10.1038/s41418-017-0007-1) contains supplementary material, which is available to authorized users.

Halima Ouadid-Ahidouch

halima.ahidouch-ouadid@u-picardie.fr

$\triangle$ Philippe Kischel

Philippe.Kischel@u-picardie.fr

1 Université de Picardie Jules Verne, UFR des Sciences, Laboratoire de Physiologie Cellulaire et Moléculaire (EA 4667), SFR CAPSANTE (FED 4231), Amiens, France

2 Department of Medical Biology L2-109, Academic Medical Center-University of Amsterdam Meibergdreef 9 1105AZ Amsterdam, The Netherlands

3 Equipe Signalisation, Apoptose et Cancer CNRS UMR8161, Institut de Biologie de Lille - Institut Pasteur 1 Rue Pr. Calmette, CS50447 59021 Lille Cedex, France hindrance for effective therapeutic modalities. Despite significant advances in early detection, as well as comprehension of molecular mechanisms of breast cancer (BC), about $30 \%$ of patients with early-stage $\mathrm{BC}$ have recurrent disease [1]. In general, systemic agents such as chemotherapeutic drugs are effective in $90 \%$ of primary BC. However, progression generally occurs over time, and if such, resistance to therapy is not only common but quite expected [1]. Residual tumor cells are detected post-treatment in most cancer patients, and these cells are thought to remain in a quiescent state for years before resuming growth, resulting in tumor recurrence. Tumor cells from recurrent tumors exhibit increased resistance to chemotherapeutic drugs [2], and become more difficult to eradicate. Deciphering molecular mechanisms of this acquired cellular resistance not only would be a major step toward comprehension and finding on how to eradicate cancer cells, but could also serve for predicting tumor resistance, allowing more personalized treatments for the patient's benefit.

Altered expression of ion channels is now recognized as one of the hallmarks of cancer [3], and several ion channels have already been proposed as novel emerging biomarkers and targets for cancer therapy [4]. Among them, calcium channels are of particular interest, calcium being a wellknown ubiquitous second messenger regulating a wide variety of physiological functions [5, 6], including cell proliferation and cell death [7]. Store-operated calcium 

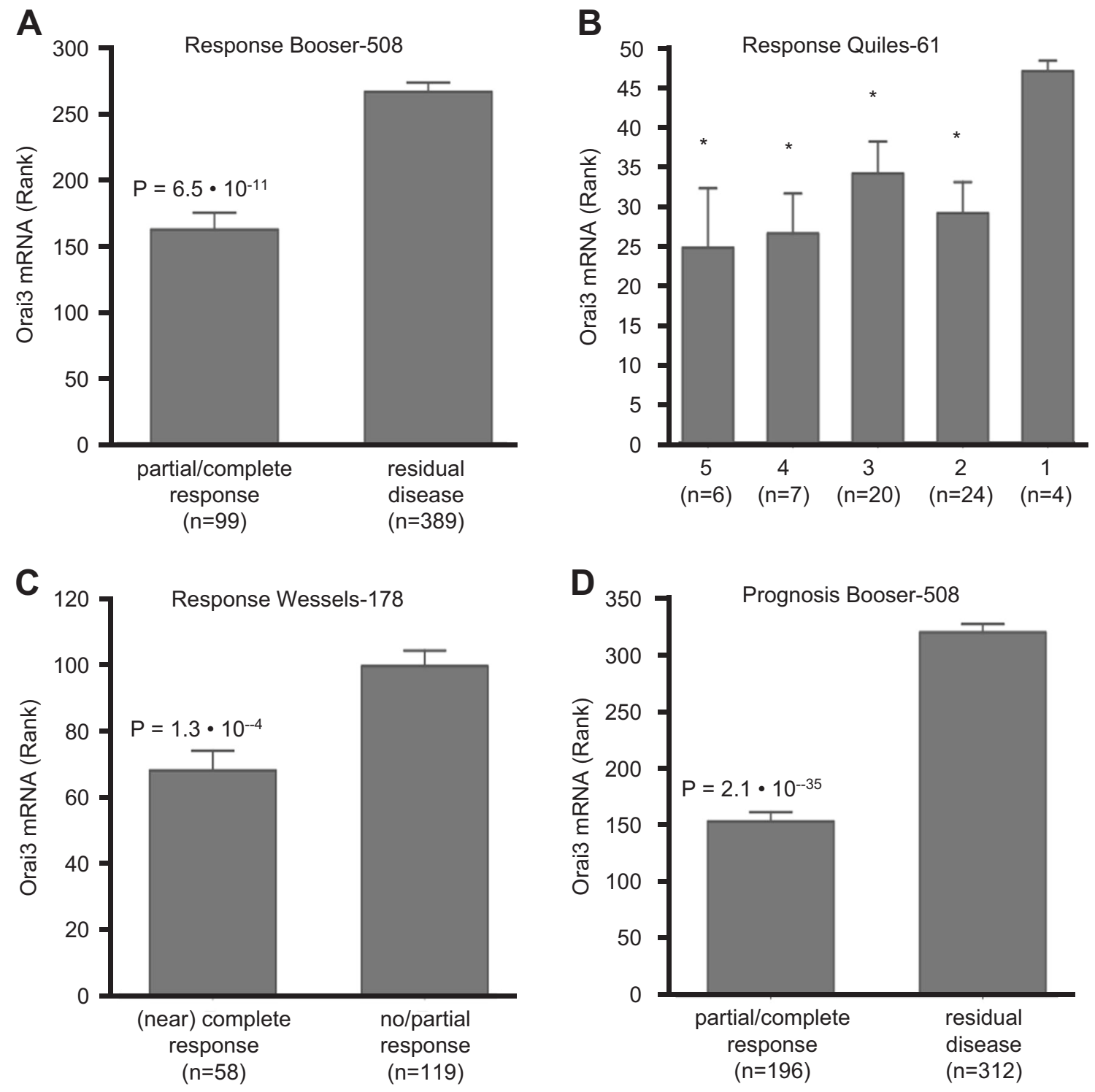

Fig. 1 ORAI3 mRNA expression and therapy response in public BC datasets. A, B and C Orai3 mRNA-therapy response correlation plots. Orai3 tumor mRNA expression correlation with response to chemotherapy treatment is shown for the Booser-508 (A), Quiles-61 (B), and Wessels-178 (C) data sets. Treatment regimens were taxaneanthracycline in Booser-508 and Quiles-61, and doxorubicincyclophosphamide in Wessels-178. Samples were grouped on partial/complete response $v s$. residual disease in Booser-508 and Wessels178. In Quiles-61, samples were grouped according to the Miller and

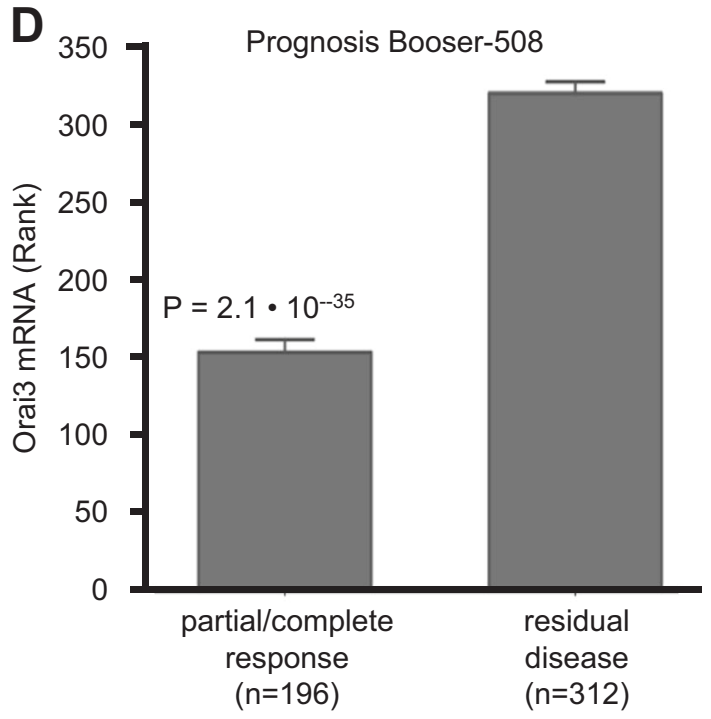

Payne response grade [51], from 5 (good response) to 1 (poor response). * indicates $p<0.05$. In all three data sets, Orai3 tumor mRNA expression is significant lower in tumors showing good therapy response. D Orai3 mRNA-therapy response prediction correlation plot. For the Booser-508 data set, the DLDA-30 30-gene expression profile predicting therapy response [52] was available. The correlation plot shows that low Orai3 tumor mRNA expression is statistically significant predictive for (near) complete therapy response.

entry (SOCE) is one of the main calcium entry in nonexcitable cells, and typically allows calcium influx through the plasma membrane subsequently to endoplasmic reticulum depletion. This ubiquitous SOCE pathway is not only necessary to refill internal calcium stores, but also to activate downstream signaling cascades [8]. Apoptosis is also potentially triggered when a large and sustained rise in cytosolic calcium occurs through SOCE (mediated by store-operated channels (SOCs)) [9-11]. Actors of this

mechanism include depletion sensors (STIM reticular proteins), as well as plasma membrane channels. Among these, Orai channels represent highly selective calcium channels, with three distinct Orai isoforms described to date (Orai1, Orai2, and Orai3). While far less studied than Orai1, Orai3 protein deserves special attention, because of (i) its exclusive presence in mammals [12], (ii) its receptivity to pharmacological modulation [13], and (iii) its recent emergence in the cancer field, especially in BC. For 
instance, our group recently reported that Orai3 channels are overexpressed in BC biopsies, and are involved in proliferation, cell cycle progression, and survival of $\mathrm{BC}$
[14]. Moreover, these effects appear to be specific to cancer cells [14], and are transduced—at least in part—via the c-myc pathway [15].
Fig. 2 Orai3 overexpression induces resistance to cell death. Proliferation rates are not affected by Orai3

overexpression in normal conditions (5\% FCS, $72 \mathrm{~h}, \mathbf{A})$. Cell mortality is reduced upon Orai3 overexpression ( $72 \mathrm{~h}, \mathbf{B})$. Orai3 overexpression promotes cell resistance to the classical apoptosis inducers thapsigargin (Tg, $1 \mu \mathrm{M}, 24 \mathrm{~h}, \mathbf{C})$ and staurosporine (STS, $1 \mu \mathrm{M}, 6 \mathrm{~h}$, D). Orai3 overexpression also promotes cell resistance to chemotherapeutic drugs, including cisplatin (Cisp., $5 \mu \mathrm{M}$, $24 \mathrm{~h}, \mathbf{E}), 5-\mathrm{FU}$ (5-FU., $40 \mu \mathrm{g} / \mathrm{ml}$, $48 \mathrm{~h}, \mathbf{F}$ ) and paclitaxel (Pac., $100 \mathrm{nM}, 48 \mathrm{~h}, \mathbf{G})$. Values are reported as mean \pm SEM. $* p<$ $0.05 v s$. control
A

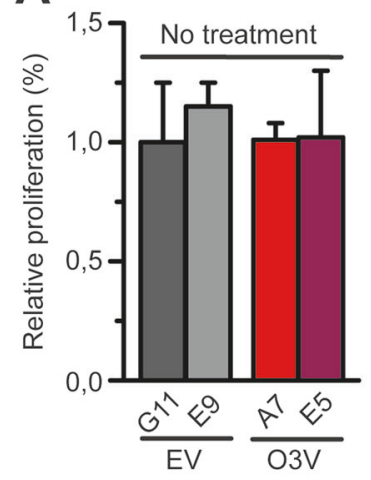

$\mathrm{C}_{50}$

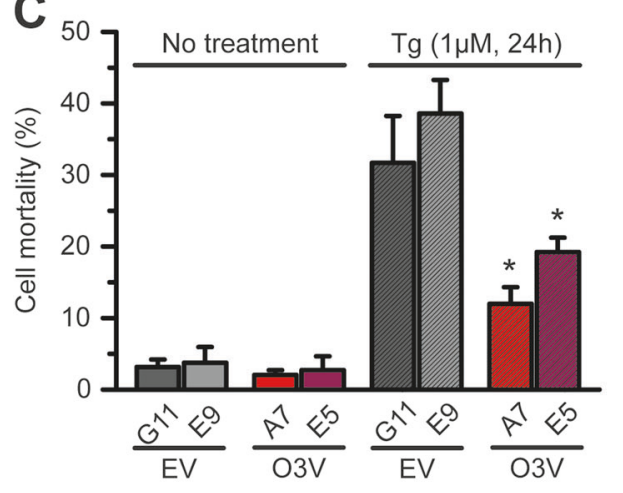

E

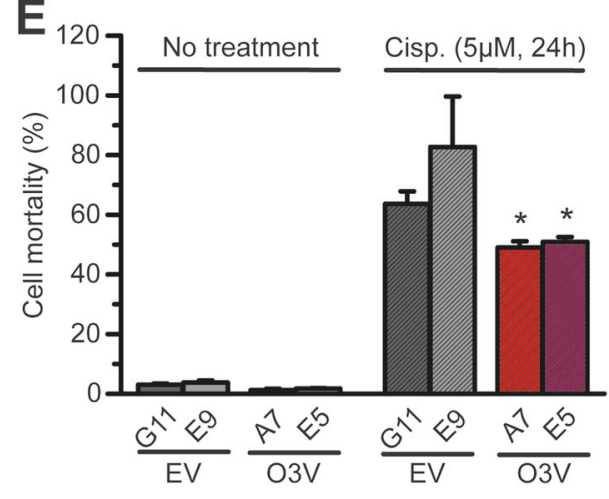

G

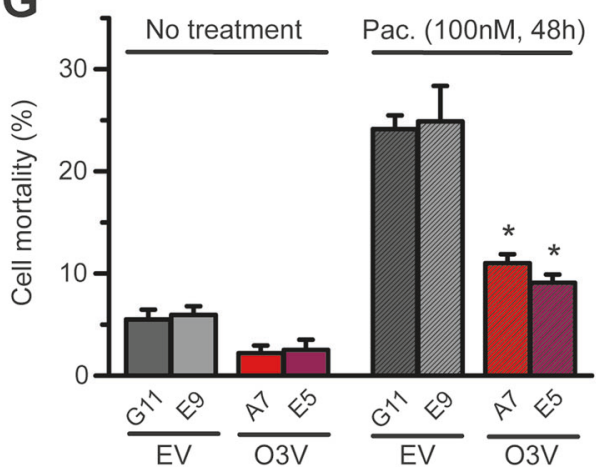

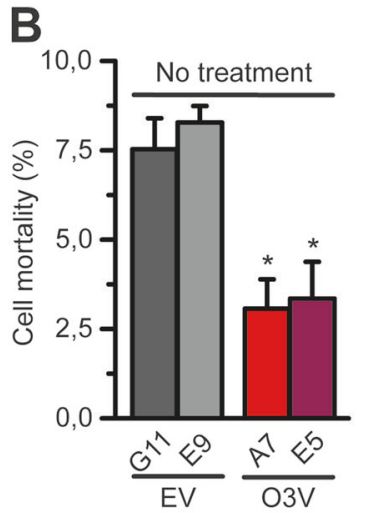
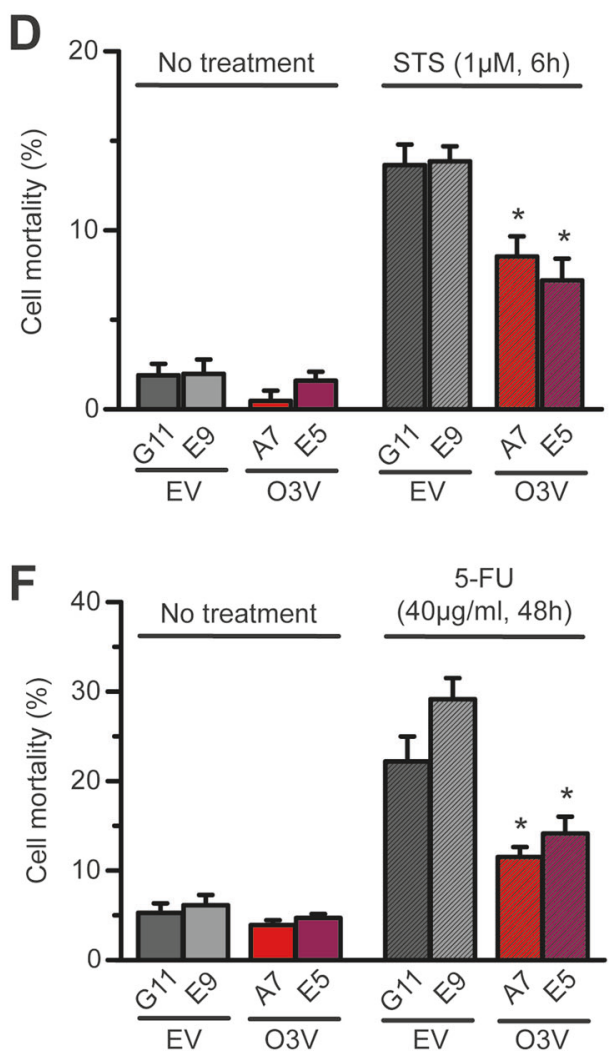

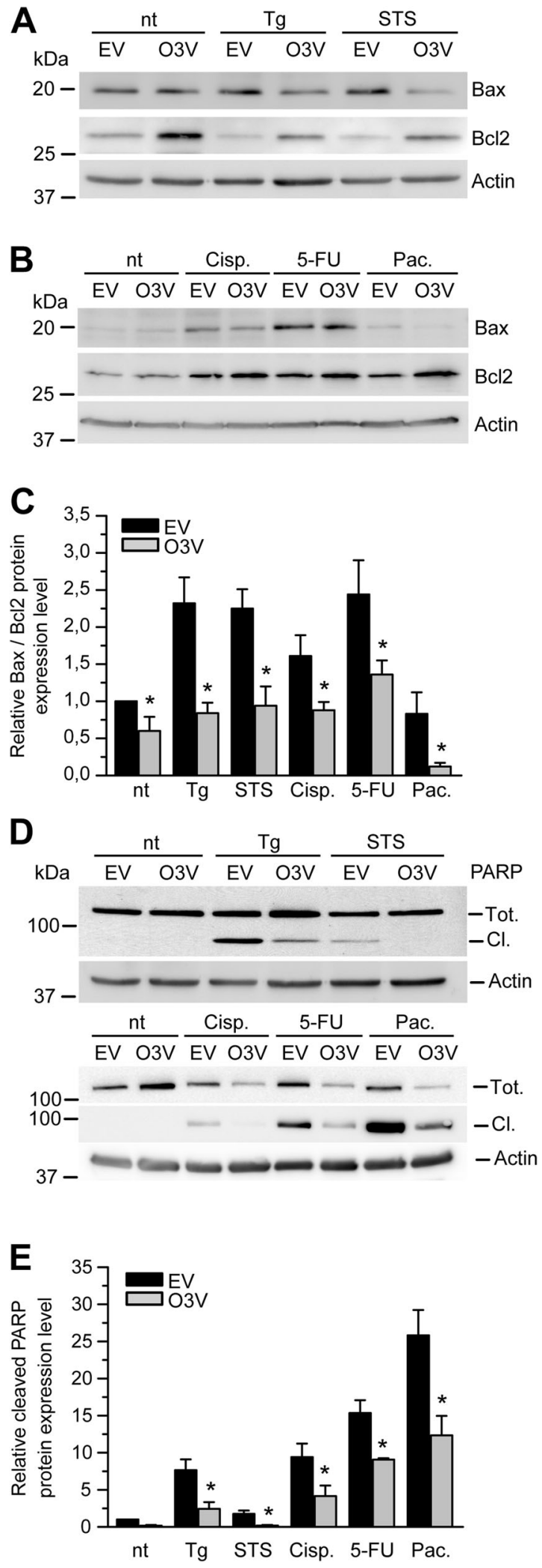

Herein, we investigated the phenotypical effects of Orai3 overexpression in $\mathrm{ER}^{+} \mathrm{BC}$ cell, in which SOCE is Orai3dependent [16]. In concordance with bioinformatic data
Fig. 3 Orai3 overexpresion leads to decreased apoptosis in BC cells. Representative western blot showing the effect of Orai3 overexpression on Bax and Bcl-2 expression, without treatment (no treatment, nt), and after treatment with the classical apoptosis inducers thapsigargin and staurosporin (A), and the chemotherapeutic drugs cisplatin (Cisp.), 5-fluorouracile (5-FU), and paclitaxel (Pac., B). Analysis of $\mathrm{Bax} / \mathrm{Bcl}-2$ ratio for all treatments is shown in $\mathbf{C}$ (all values are normalized to $\mathrm{EV} \mathrm{nt}$, and all treated-EV values-except the paclitaxel one-are significantly different from the EV nt value). D Representative western blot showing the effect of Orai3 overexpression on PARP cleavage after treatment with either the classical apoptosis inducers (Tg and STS) or the chemotherapeutic drugs (Cisp., 5-FU, and Pac.). Analysis of cleaved PARP protein expression for all treatments is shown in $\mathbf{E}$ (all values are normalized to $\mathrm{EV} n \mathrm{nt}$, and all treated-EV values-except the STS one-are significantly different from the EV nt value). Values are reported as mean \pm SEM of triplicate experiments. $* p<0.05 v s$. control

from public BC cohorts, we show that Orai3 is indeed able to confer resistance to cell death, and activates a calciumdependent mechanism modulating the expression of the tumor suppressor protein $\mathrm{p} 53$.

\section{Results}

\section{Clonal selection as a model to study Orai3 overexpression}

To explore the potential relationship between Orai3 expression and resistance in $\mathrm{BC}$ cells, we analyzed three data sets of human $\mathrm{BC}$ data in the public domain, characterized for Orai3 messenger RNA (mRNA) expression and chemotherapy response. In all data sets, Orai3 mRNA expression was higher in tumors from patients with poor response and/or residual disease than those from patients with partial or complete therapy response (Fig. 1D and Supplementary Information). High Orai3 mRNA expression in the tumor sample was predictive of poor patient outcome (Fig. 1D and Supplementary Information). To validate these bioinformatic analyses, stable Orai3overexpressing $(\mathrm{O} 3 \mathrm{~V}) \mathrm{T} 47 \mathrm{D}$ BC clones were selected. Messenger RNA was overexpressed $>200 \times$ in O3V-A7 clone and around $150 \times$ in O3V-E5 clone vs. empty vector $(\mathrm{EV})$ clones, respectively (Fig. S1A). Overexpression was also seen at the protein level (Fig. S1B). Calcium imaging experiments using 2APB (which activates Orai3 but inhibits Orai1 and Orai2 [16, 17]) indicated that these overexpressed channels were functional (data not shown). Resting $\left[\mathrm{Ca}^{2+}\right]_{\mathrm{i}}$ significantly increased in O3V cells when compared to EV cells (Fig. S1C). Orai3 overexpression was also able to increase basal SOCE (Fig. S1D). Orai3 transient transfection was also performed in the Cos-7 cell line: mRNA and proteins were largely overexpressed (Fig. S1A, B), and SOCE was also increased (Fig. S1D). Overexpression levels obtained in T47D cells were compared to expression levels obtained in some tumors (Fig. S1E and Supplementary Information). To extend these 
observations, we also show a higher Orai3 DNA copy number and mRNA overexpression in the three aggressive subtypes of the three largest BC data sets on the Oncomine website (Supplementary Information and Fig. S1F, G, and H). These data suggest a tumor-promoting role for Orai3 in aggressive BC.

\section{Phenotypical changes induced by Orai3 overexpression}

\section{Orai3 overexpression decreases cell mortality}

Proliferation rates are not affected by Orai3 overexpression, either in $5 \%$ FCS (Fig. 2A) or in serum-depleted media $(0 \%$ FCS, data not shown). Cell mortality is however reduced in O3V cells (Fig. 2B), on average to half of the mortality seen in EV cells at 24,48 , or $72 \mathrm{~h}$. In the $0 \%$ FCS condition, the effect of Orai3 overexpression is even stronger, with mortality being up to $3 \times$ lower than in EV clones (Fig. S2A).

\section{Orai3 promotes cell resistance to classical apoptosis inducers}

We next wondered whether O3V cells would also be less prone to mortality under stressful conditions, using apoptosis inducers such as thapsigargin (Tg) and staurosporine (STS). With $1 \mu \mathrm{M}$ Tg, EV cells exhibited almost $40 \%$ mortality (24 h, Fig. 2C). O3V cells, on the other hand, showed $<20 \%$ mortality in the same conditions. Upon STS application $(6 \mathrm{~h})$, cell mortality increased up to $14 \%$ in EV clones (Fig. 2D), whereas cell mortality was $<8 \%$ in $\mathrm{O} 3 \mathrm{~V}$ clones.

\section{Orai3 promotes cell resistance to chemotherapeutic drugs}

We next used chemotherapeutic drugs, such as cisplatin (a DNA alkylating-like agent), 5-fluorouracil (5-FU, a pyrimidine analog that acts through thymineless death), and paclitaxel (a taxane that interferes with the normal breakdown of microtubules during cell division). $\mathrm{O} 3 \mathrm{~V}$ cells were found to be resistant to all agents (Fig. 2E, F and G for cisplatin, 5-FU and paclitaxel, respectively). Since results obtained with both EV clones and both $\mathrm{O} 3 \mathrm{~V}$ clones were highly similar, we chose to continue with only one clone of each category: from now on, and unless otherwise stated, EV-G11-T47D and O3V-A7T47D clones will be referred to as EV and O3V, respectively.

\section{Orai3 overexpression leads to decreased apoptosis in $\mathrm{BC}$ cells}

Bax was demonstrated to heterodimerize with Bcl-2 and suppress its ability to block apoptosis [18]. The Bax/Bcl-2 ratio determines thus cellular survival or apoptotic cell death [19]. In O3V-T47D cells, the $\mathrm{Bax} / \mathrm{Bcl}-2$ ratio decreased vs. EV cells. This effect was enhanced by treatments, either with the classical apoptosis inducers $\mathrm{Tg}$ and STS (Fig. 3A, C), or with the chemotherapeutic drugs cisplatin, 5-FU, and paclitaxel (Fig. 3B, C).

PARP (poly(ADP-ribose) polymerase) cleavage results in inactivation of the enzyme [20], and is a common feature of apoptosis. Cleaved PARP was clearly decreased in O3VT47D cells treated with Tg, STS, cisplatin, 5-FU, and paclitaxel (Fig. 3D, E). O3V cells were also resistant to etoposide and pemetrexed (Fig. S2B). We also extended these observations to a non-tumoral cell line (Cos-7), using transient transfection. O3V-Cos-7 cells were resistant to paclitaxel (Fig. S2C), as well as cisplatin and STS (Fig. S2D). Together, these results demonstrate that Orai3 overexpression was able to confer protection against several apoptosis inducers in $\mathrm{BC}$ and Cos-7 cells.

\section{p53 is a key player in Orai3-conferred resistance}

\section{Orai3-conferred resistance is $\mathrm{p} 53$-dependent}

Using a high-throughput Affymetrix screening method, we obtained an overview of the genes regulated by Orai3 overexpression (Supplementary Table 1). Several genes linked to death resistance were found to be regulated by the tumor suppressor gene TP53. Notably, FOXO1 (Forkhead box protein O1), AREG (coding for amphiregulin), and $C A L B 2$ (coding for calbindin-2) were found downregulated in $\mathrm{O} 3 \mathrm{~V}$ cells $(1.55 \times, 6.07 \times$ and $7.32 \times v s$. EV cells, respectively). These results were confirmed by qRT-PCR (Fig. 4A). It clearly appeared that p53 protein expression, as well as its transcriptional target $\mathrm{p} 21$, were downregulated in O3V cells (Fig. 4B). p53 and p21 protein expressions, although induced by different chemotherapeutic treatments, remained lower in O3V cells (Fig. 4C). p53 downregulation was also observed in O3V-MCF7 stable clones (Fig. S3A).

\section{Orai3-conferred resistance appeared dependent on p53 transcriptional activity}

p53 is mutated in T47D cells (L194F), but retain some transcriptional activity [21]. p53 downregulation was indeed paralleled by a downregulation of p21 mRNA expression (Fig. 4D) and p21 protein expression (Fig. 4C), as well as numerous other genes (FOXO1, CALB2, and $A R E G$ for instance, see above). Treatments with pifithrin- $\alpha$ (an inhibitor of p53 transcriptional activity) decreased p21 expression (Fig. 4D). In wild-type ${ }^{\mathrm{wt}} \mathrm{p} 53 \mathrm{MCF} 7-\mathrm{O} 3 \mathrm{~V}$ cells, 
A

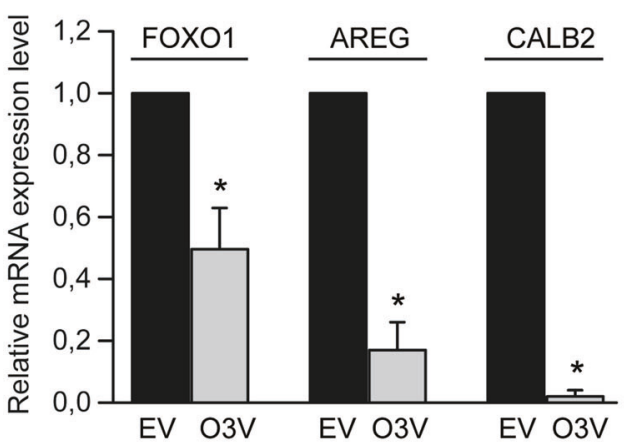

C

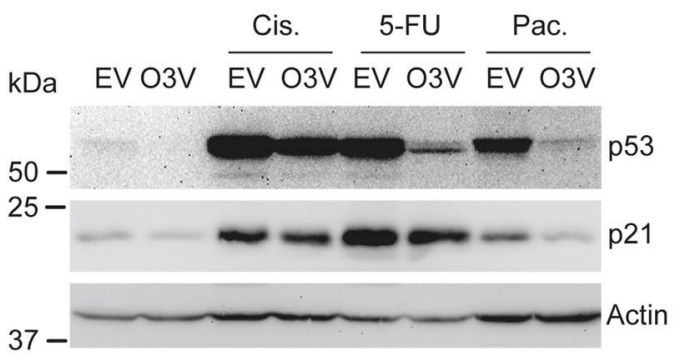

E

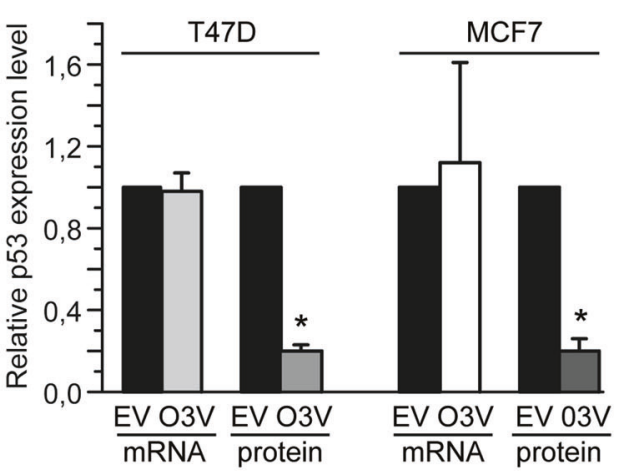

G

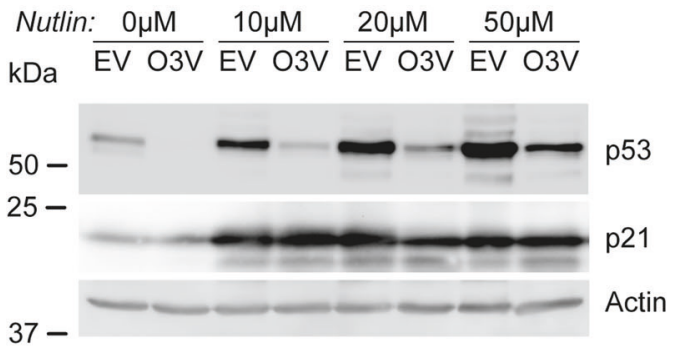

B
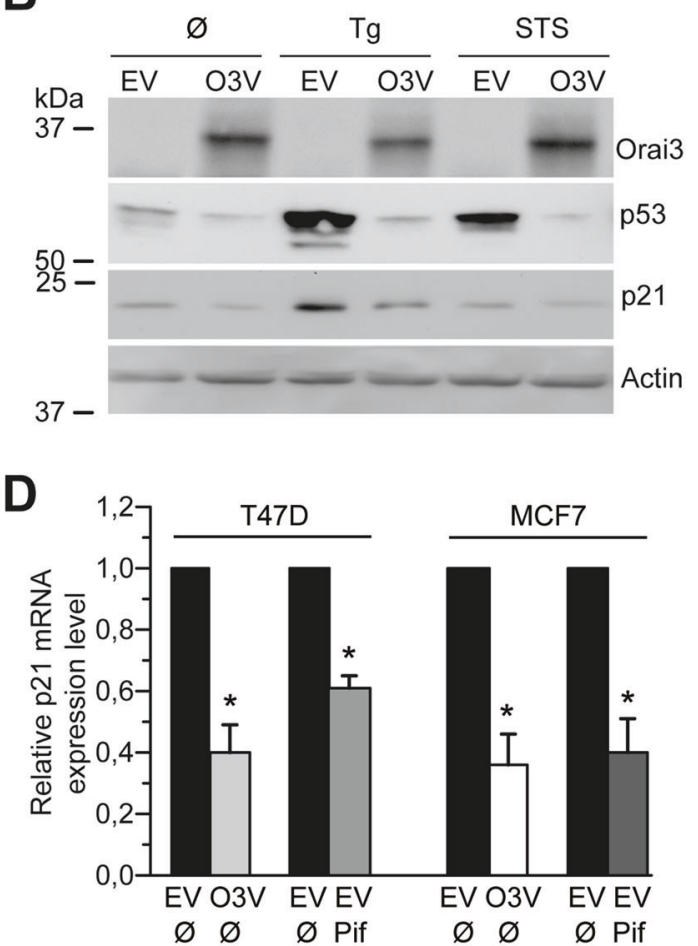

$F$

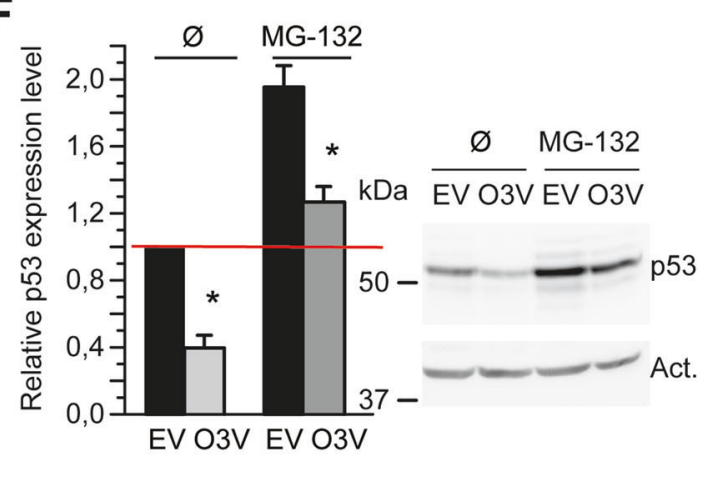

H

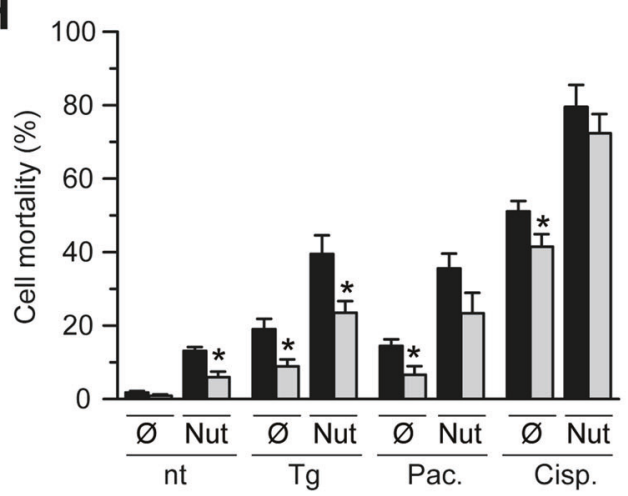


Fig. 4 p53 is a key player in the Orai3-conferred resistance. A Relative transcript levels of several genes regulated by p53 at the transcriptional level: Foxo1, amphiregulin, calbindin-2, (FOXO1, AREG, and CALB2, respectively), in both empty vector (EV) and in Orai3overexpressing T47D cells $(\mathrm{O} 3 \mathrm{~V})$. mRNAs are normalized to $B$-actin, as described in the Methods section. Western blots showing p53 and p21 downregulation in Orai3-overexpressing T47D cells treated with the classical apoptosis inducers Tg and STS (B) the different chemotherapeutic drugs $(\mathbf{C})$, with p53 expression levels remaining systematically lower in Orai3-overexpressing cells. The exposure times are different in $\mathbf{b}$ and $\mathbf{C}$, to avoid overexposure of p53 bands in chemotherapy-treated samples. D Relative transcript levels of p21 (regulated by p53 at the transcriptional level), in both EV and $\mathrm{O} 3 \mathrm{~V}$ T47D cells. EV cells were also treated with pifithrin- $\alpha$, a p53dependent gene transcription inhibitor. E p53 does not appear to be regulated at the transcriptional level (mRNA), neither in T47D, nor in MCF7 cells. At the protein level, p53 is downregulated in both cell lines. F Relative p53 protein expression in both EV and O3V cells, treated or not with the proteasome inhibitor MG-132. G Cells were treated with 10,20 , and $50 \mu \mathrm{M}$ of the Mdm2 inhibitor nutlin-3: following treatment, both $\mathrm{p} 53$ and $\mathrm{p} 21$ protein expression increased. With the $20 \mu \mathrm{M}$ concentration, p53 levels in O3V (lane 6) reached expression levels seen in EV cells. Values are reported as mean \pm SEM of triplicate experiments. H Cell mortality in EV and O3V T47D cells, treated with thapsigargin (Tg), paclitaxel (Pac.), and cisplatin (Cisp.), with or without nutlin. Mortality in $\mathrm{O} 3 \mathrm{~V}$ cells treated with $\mathrm{Tg}+$ nutlin reached the same level than $\mathrm{EV}$ treated with $\mathrm{Tg}$ alone (this is also true for paclitaxel treatments). $* p<0.05 v s$. control

p21 was also downregulated (Fig. 4D). We next wondered whether Orai3 expression in BC samples of human patients was connected to p53 mutant or wild-type activity. In two data sets (from cBioPortal) annotated for p53 and Orai3 status, Orai3 DNA copy gain and mRNA overexpression occurred mainly in tumors with ${ }^{\mathrm{wt}} \mathrm{p} 53$ (Fig. S4). This suggests that in human BC, Orai3 depends on p53 function for its tumor-promoting activity.

\section{p53 is not regulated at the transcriptional level}

p53 protein expression was decreased up to $80 \%$ in both $\mathrm{O} 3 \mathrm{~V}$ cell lines. However, no variation of p53 mRNA was found, neither by Affymetrix screening, nor by qRT-PCR (Fig. 4E). p53 expression was restored upon treatment with the proteasome inhibitor MG-132 in O3V cells (Fig. 4F). Among the p53 regulators are E3 ubiquitin ligases, which target p53 for degradation by the proteasome. Mdm2 for instance is able to regulate both wild-type and mutated p53 [22]. When O3V cells were treated with $20 \mu \mathrm{M}$ nutlin-3 (an inhibitor of the p53-Mdm2 interaction), p53 expression returned to levels seen in EV cells (Fig. 4G). Interestingly, Orai3-conferred resistance was abolished (Fig. 4H), suggesting that Orai3-induced p53 downregulation is indeed associated with lower mortality and increased resistance. Orai3 expression had no impact on p53 subcellular location (Fig. S3B).

\section{Which signaling pathway(s) is (are) involved in Orai3-conferred death resistance?}

\section{Orai3-conferred resistance is dependent on calcium entry}

Orai3-conferred resistance was abrogated in a "calciumfree" medium (Fig. 5A), suggesting that the resistance depended on Orai3 function. Moreover, in the calcium-free medium, it clearly appeared that Orai3 overexpression was no longer able to downregulate p53 (Fig. 5B), suggesting that calcium entry through Orai3 channels was responsible for p53 downregulation. Same results were obtained with two O3V-MCF7 stable clones (Fig. S3A, lanes four to six). An immunofluorescent staining confirmed a p53 increase after siOrai3 treatment of O3V-T47D cells, and showed that p53 remained located in the nucleus (Fig. S5).

\section{The signaling pathway is PI3K-dependent}

We first used protein arrays to evaluate apoptosis actors potentially involved in the p53 downregulation. Since no candidates were found (Fig. S6), we assessed some other potential calcium-dependent pathways. We showed that NFAT (Nuclear Factor of Activated T-cells) was not implicated, using cyclosporin A (Fig. S7A) or using a reporter luciferase assay (Fig. S7B). We next inhibited calmodulin using calmidazolium chloride (Fig. S7C), calmodulin-kinase II using KN-93 (Fig. S7D), and MAPK using PD98059 (Fig. S7E). All these actors were clearly not implicated in Orai3-mediated p53 downregulation. Conversely, the PI3K inhibitor LY294002 was able to cancel, at least partly, Orai3-conferred resistance (Fig. 5C). O3V cells treated with LY294002 expressed p53 at a higher level than EV cells (Fig. 5D). Consistent results were obtained with two other PI3K inhibitors (wortmannin and PIK93): p53 was re-expressed in $\mathrm{O} 3 \mathrm{~V}$ cells (Fig. 5D), suggesting that PI3K pathway is implicated in Orai3-mediated p53 downregulation.

\section{The signaling pathway is Sgk-1-dependent}

Although PI3K was implicated, pAkt and Akt expression were not altered in $\mathrm{O} 3 \mathrm{~V}$ cells (Fig. 5E). We next assessed the serum- and glucocorticoid-induced protein kinase 1 (Sgk-1) pathway, since Sgk-1 was found to be regulated by SOCE, and mediated cytoprotection against cell death in $\mathrm{ER}^{-} \mathrm{BC}$ cells [23]. Phosphorylation level of Ser422 is essential for Sgk-1 activation [24]. The ratio pSgk-1/Sgk-1 was increased upon Orai3 overexpression (Fig. 5F), indicating Sgk-1 activation. GSK650394 (known to be a specific Sgk-1 competitive inhibitor [25] was able to 


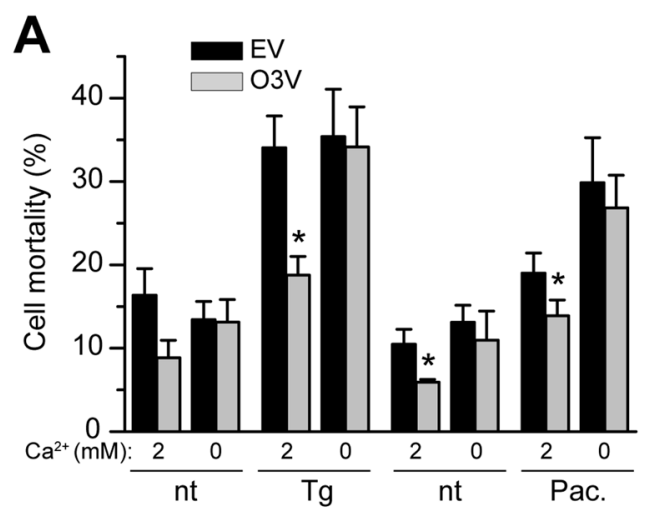

B
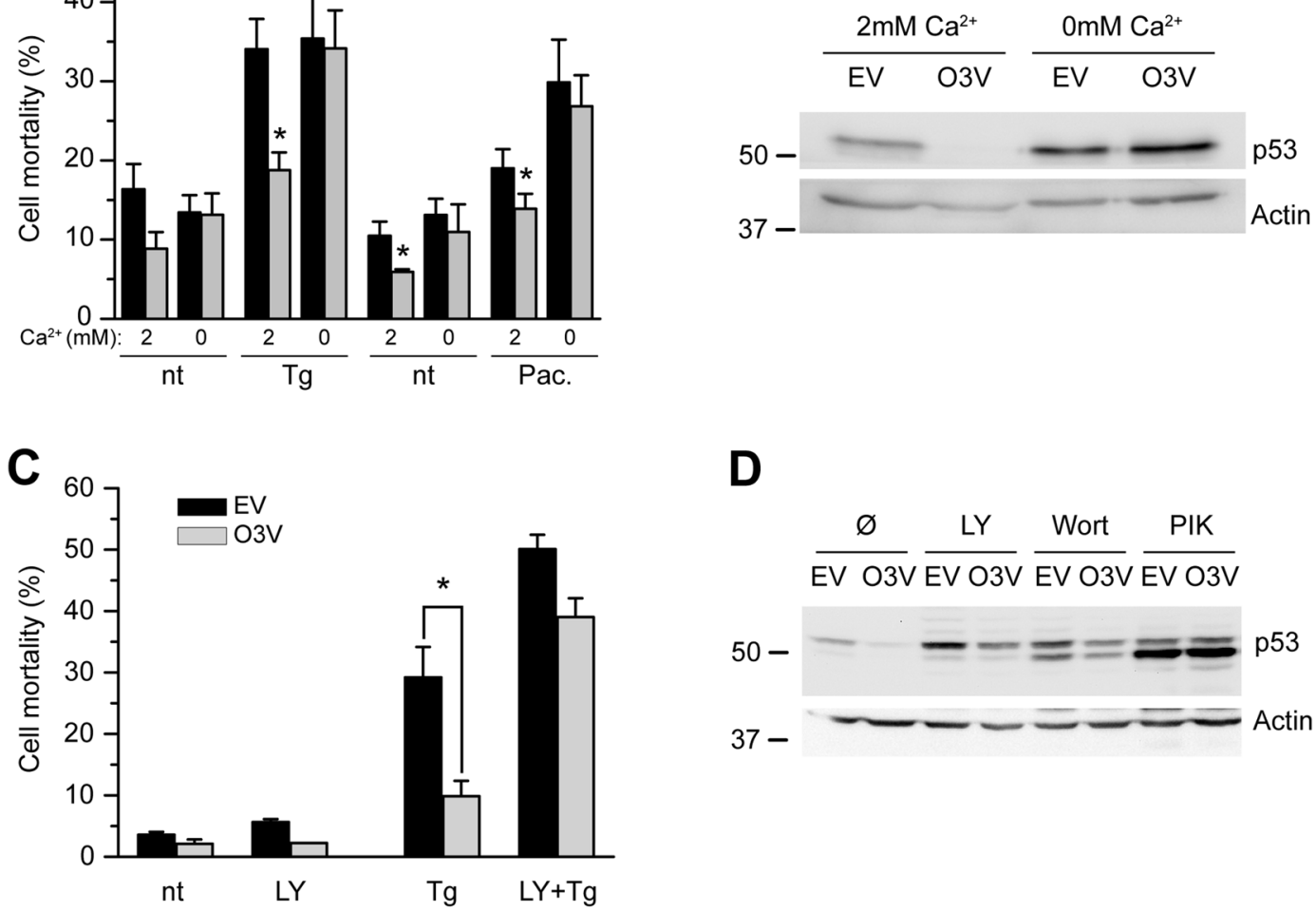

D

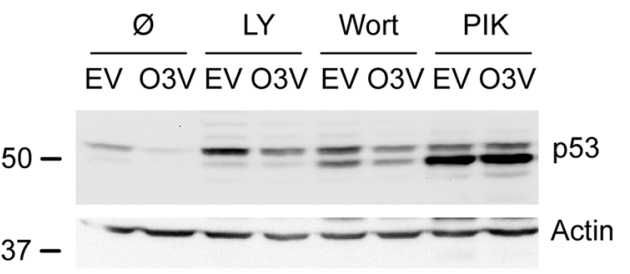

E
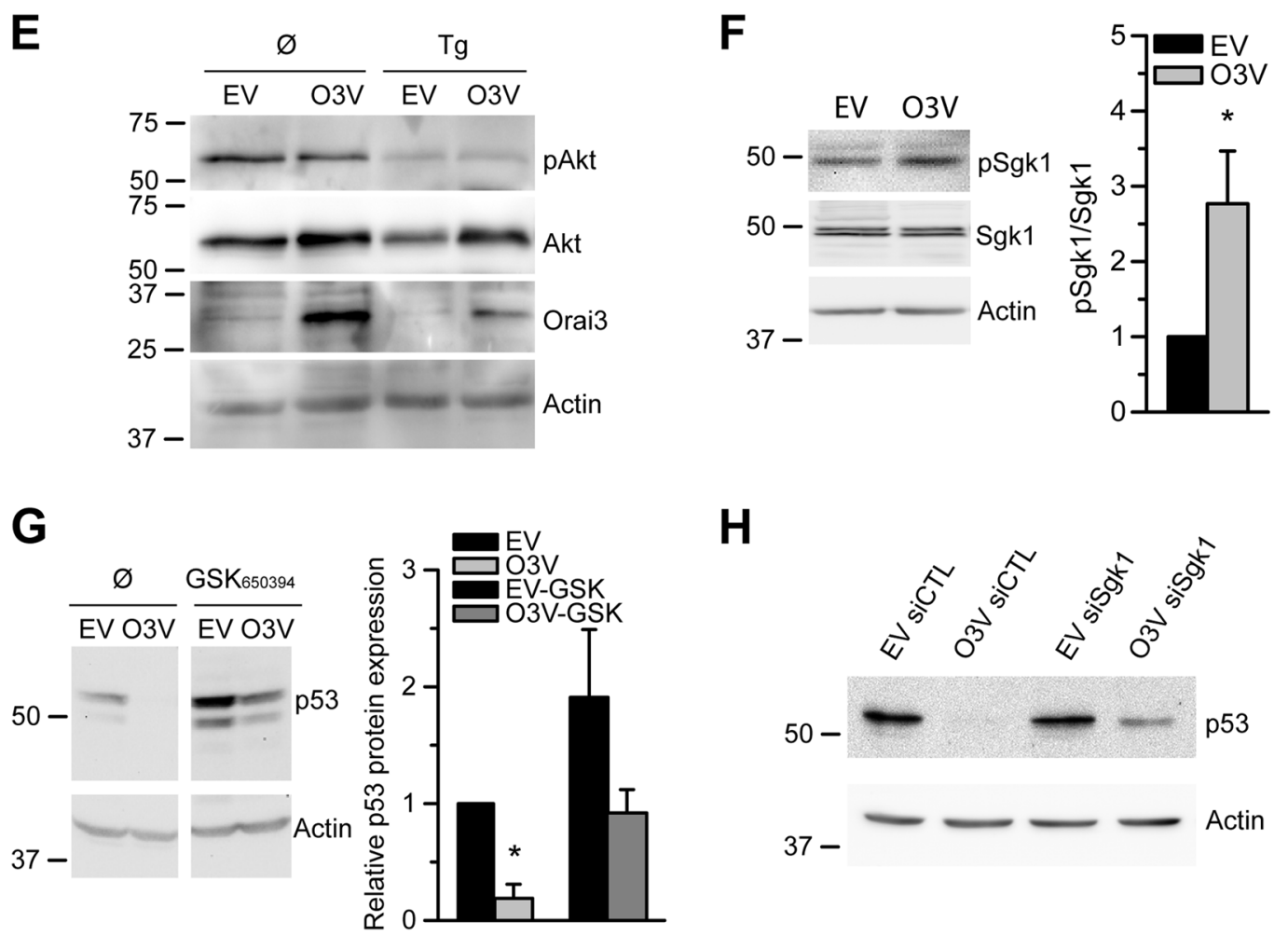

H

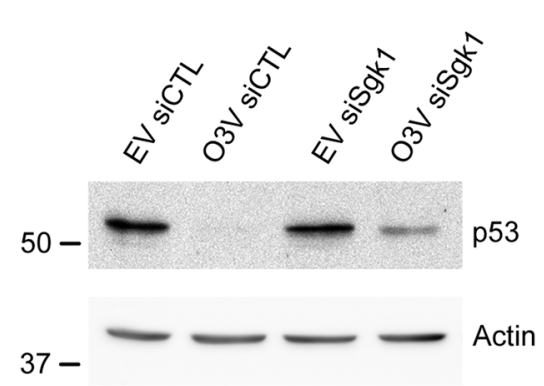

restore p53 expression in $\mathrm{O} 3 \mathrm{~V}$ cells at levels seen in control EV cells (Fig. 5G). In T47D-O3V cells, p53 level increased subsequently to Sgk-1 downregulation (Figs. $5 \mathrm{H}$ and S8A). 
Fig. 5 Orai3 overexpression stimulates the PI3K/Sgk-1 pathway in a calcium dependent manner. A: Cell mortality was assessed in T47D stable clones grown in media containing 2 or $0 \mathrm{mM}$ calcium, in the absence (no treatment, nt) and in the presence of thapsigargin $(\mathrm{Tg})$ and paclitaxel (Pac.). B Western blot showing p53 expression in EV and O3V cells upon extracellular calcium withdrawal. C Cell mortality assessed after treatment with the PI3K inhibitor LY294002 (LY, 20 $\mu \mathrm{M}$ ), in the absence (no treatment, $\mathrm{nt}$ ) and in the presence of thapsigargin (Tg, $1 \mu \mathrm{M}, 24 \mathrm{~h}$ ). D Western blot showing p53 expression after treatment with three PI3K inhibitors, LY294002, wortmannin (Wort., $200 \mathrm{nM}$ ) and PIK93 (PIK, $500 \mathrm{nM}$ ). E Western blot showing pAkt (Ser473), Akt and Orai3 expression in 0\% FCS media, in absence (Ø) and in the presence of thapsigargin ( $\mathrm{Tg})$. F Western blots showing pSgk-1 (Ser422) and Sgk-1 expression in 0\% FCS media (left). Quantification of the pSgk-1/Sgk-1 ratio is also shown (right). G p53 protein expression was evaluated in the absence $(\varnothing)$ and in the presence of the specific Sgk-1 inhibitor GSK650394 (200 nM). H p53 protein expression was evaluated by western blot in EV and $\mathrm{O} 3 \mathrm{~V}$ stable clones, transfected with either siCTL or siSgk-1. Quantification of p53 protein expression level is shown in Fig. S8A

\section{Mdm2 does not appear to be the only link between Sgk-1 and p53}

\section{p53 degradation is also mediated by an Mdm2- independent mechanism}

Mdm2 is activated by a Sgk-1-dependent Ser166 phosphorylation, inducing p53 degradation and affecting cell survival [26]. Mdm2 protein expression was drastically decreased in $\mathrm{O} 3 \mathrm{~V}$ cells (by almost $90 \%$, Fig. 6A). The ratio ${ }^{\mathrm{Ser} 166} \mathrm{Mdm} 2 / \mathrm{Mdm} 2$ was increased in O3V vs. EV cells, most probably as a result of $\mathrm{PI} 3 \mathrm{~K} / \mathrm{Sgk}-1$ pathway activation. Orai3-mediated p53 downregulation could hardly be explained by the drastic $\mathrm{Mdm} 2$ decrease. This protein downregulation was paralleled by decreased mRNA levels (Fig. 6B), probably because of the p53 transcriptional regulation of Mdm2.

\section{Is Nedd4-2 implicated in 03V-induced p53 degradation?}

Nedd4-2 is another Sgk-1-activated ubiquitin ligase. We found that Nedd4-2 downregulation was able to restore p53 protein levels (Figs. 6C and S8B). A critical site for the inactivation of Nedd4-2 by Sgk-1 is the S448 [27] residue, and the phosphorylation level of this site was found to be dramatically decreased in O3V cells (Figs. 6D and S8C).

\section{Sek-1, the missing link between Sgk-1 and Nedd4-2?}

Since activated Sgk-1 resulted in a dephosphorylated Nedd4-2, we searched either for an Sgk-1-activated phosphatase, or for an Sgk-1-inactivated kinase. Sek-1 is a kinase known to be inhibited by Sgk-1. Total Sek-1 protein was drastically decreased. Sek-1 phosphorylation level decreased less importantly (Fig. 6E), and the ratio pSek-1/ Sek-1 was thus increased in O3V cells (Fig. S8D). After calcium withdrawal, Sek-1 protein levels and pNedd4-2 were drastically increased, in EV as well as in $\mathrm{O} 3 \mathrm{~V}$ cells (Figs. 6e and S8E). Moreover, in O3V cells, increased levels of Sek-1 and pNedd4-2 in "zero calcium" external solution were associated to increased p53 levels (Fig. 5B). When silencing Sek-1 in T47D-EV cells (expressing activated Sek-1), protein expression levels of pNedd4-2 and p53 were decreased, but not the Nedd4-2 expression (Figs. 6F and S8F).

\section{Discussion}

The appearance of cell resistance to chemotherapies is the major cause of relapse and metastasis, by allowing cancer cells to spread and grow at distant sites from the primary tumor [28]. We hypothesized that Orai3, a calcium channel upregulated in breast tumors and involved in apoptosis [14], would be able to play a role in cell resistance. In BC cells, Orai3 upregulation increased SOCE. Interestingly, resistance of prostate cancer (PC) cells was also linked to an Orai member (Orai1), but this resistance was conferred by a reduced SOCE $[9,10,29,30]$. The resistance found in PC cells is thought to be a consequence of newly formed heteromeric Orai1/Orai3-based channels, at the expense of homomeric Orail and/or Orai3-based SOCs [30]. Results obtained in PC and BC cells are however hardly comparable, because Orail is the main Orai isoform implicated in SOCE in PC cells [30]. In these cells, Orai3 overexpression also shifts the balance of predominant $\mathrm{Ca}^{2+}$ entry pathways from store-dependent ones to arachidonic acid (AA)dependent ones [30]. AA-dependent calcium entry was however not modified in our BC cell lines overexpressing Orai3 (data not shown). Orai3 channels may thus preferably work in a homomeric state in $\mathrm{ER}^{+}-\mathrm{BC}$ cells, and Orai3 overexpression may only increase the proportion of active Orai3 channels. This hypothesis is supported by the increased SOCE (which could appear quite modest, but without concomitant Stim1 overexpression, the pool of endogenous Stim1 is likely to be the limiting factor of SOCE amplitude).

Both classical apoptosis inducers and chemotherapeutic drugs used in this study were limited in inducing mortality in Orai3-overexpressing cells: this finding suggests a common mechanism. Our high-throughput transcriptomic analysis suggested a p53-dependent Orai3-conferred resistance. We showed a p53 downregulation in T47D cells (harboring a mutated p53), as well as in MCF-7 cells (p53 wild type). However, we confirm that the ${ }^{\mathrm{L} 194 \mathrm{~F}} \mathrm{p} 53$ mutant in T47D cells retains some transcriptional activity, in good 
Fig. 6 Implication of ubiquitinligases in Orai3-mediated p53 downregulation. A Western blot showing pMdm2 (Ser166) and Mdm2 expression in $0 \%$ FCS media (left), and quantification of the pMdm2/Mdm2 ratio (right). B Relative Mdm2 transcript levels in T47D stable clones. C Cells were transfected with small interfering RNAs targeting Nedd4-2, and p53 protein expression was assessed by western blot. Quantification of $\mathrm{p} 53$ protein expression level is shown in Fig. S8B. D Western blot showing pNedd4-2

(Ser448) and Nedd4-2

expression with or without $\mathrm{Tg}$ treatment. Quantification of the pNedd4-2/Nedd4-2 ratio is shown in Fig. S8C. E Western blot showing pSek-1 (Ser80), Sek-1, pNedd4-2 (Ser448), and Nedd4-2 expression, in EV and $\mathrm{O} 3 \mathrm{~V}$ cells, in media containing 2 or $0 \mathrm{mM}$ calcium.

Quantifications of the pSek-1/ Sek-1 and pNedd4-2/Nedd4-2 ratios are shown in Fig. S8D and E. F Western blot showing Sek1, pNedd4-2 (Ser448), Nedd4-2, and p53 expression in EV cells transfected with small interfering RNAs targeting Sek1. Quantifications of Sek-1, pNedd4-2, and p53 are shown in Fig. S8F
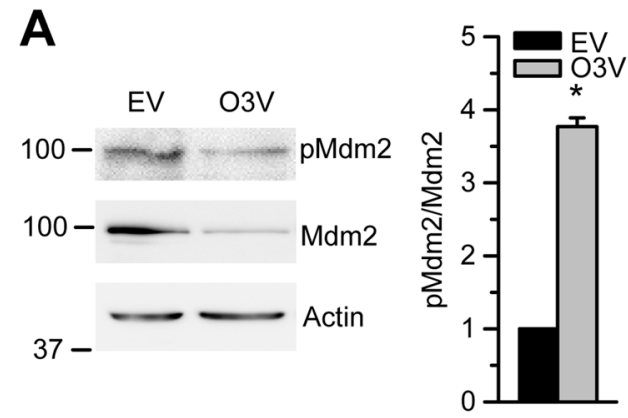

B
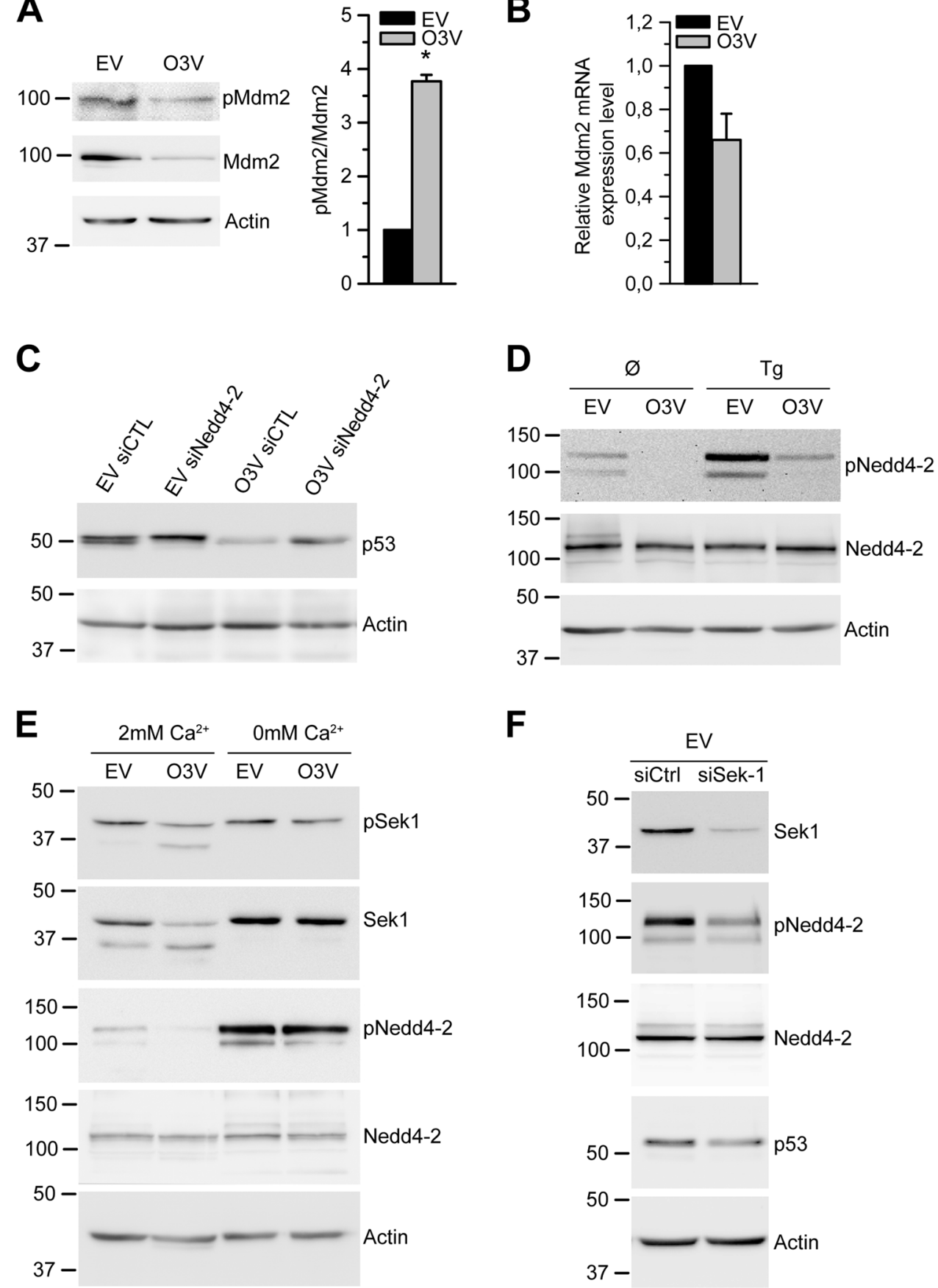

$\mathbf{F}$

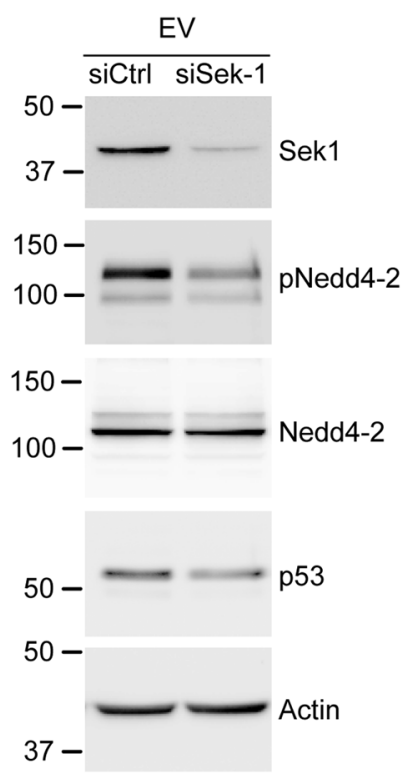

agreement with the literature [21], and the Orai3-conferred resistance is therefore likely dependent on p53 transcriptional activity, shown to be important for its pro-apoptotic function [31]. In line with this hypothesis, our bioinformatic results on large cohorts suggested that in human BC, Orai3 overexpression occur in BC cells that have no TP53 mutation, loss, or lower mRNA expression. Also in line with the above-mentioned hypothesis, we found that p53 was located in the nucleus, even upon Orai3 overexpression (Fig. S3B). This observation is relevant because transcription-independent mechanisms have already been demonstrated for p53, notably at the endoplasmic reticulum where p53 regulates apoptosis in a $\mathrm{Ca}^{2+}$-dependent manner [32]. Decreased nuclear p53 was therefore an important step for the development of Orai3-conferred resistance. For instance, p53 antagonizes Bcl-2 function at several levels, including the negative regulation of $\mathrm{Bcl}-2$ expression at the transcriptional level [33]. Bcl-2 was found to be upregulated in $\mathrm{BC}$ cell lines with all treatments, and is likely to be responsible, at least in part, for the increased resistance. 


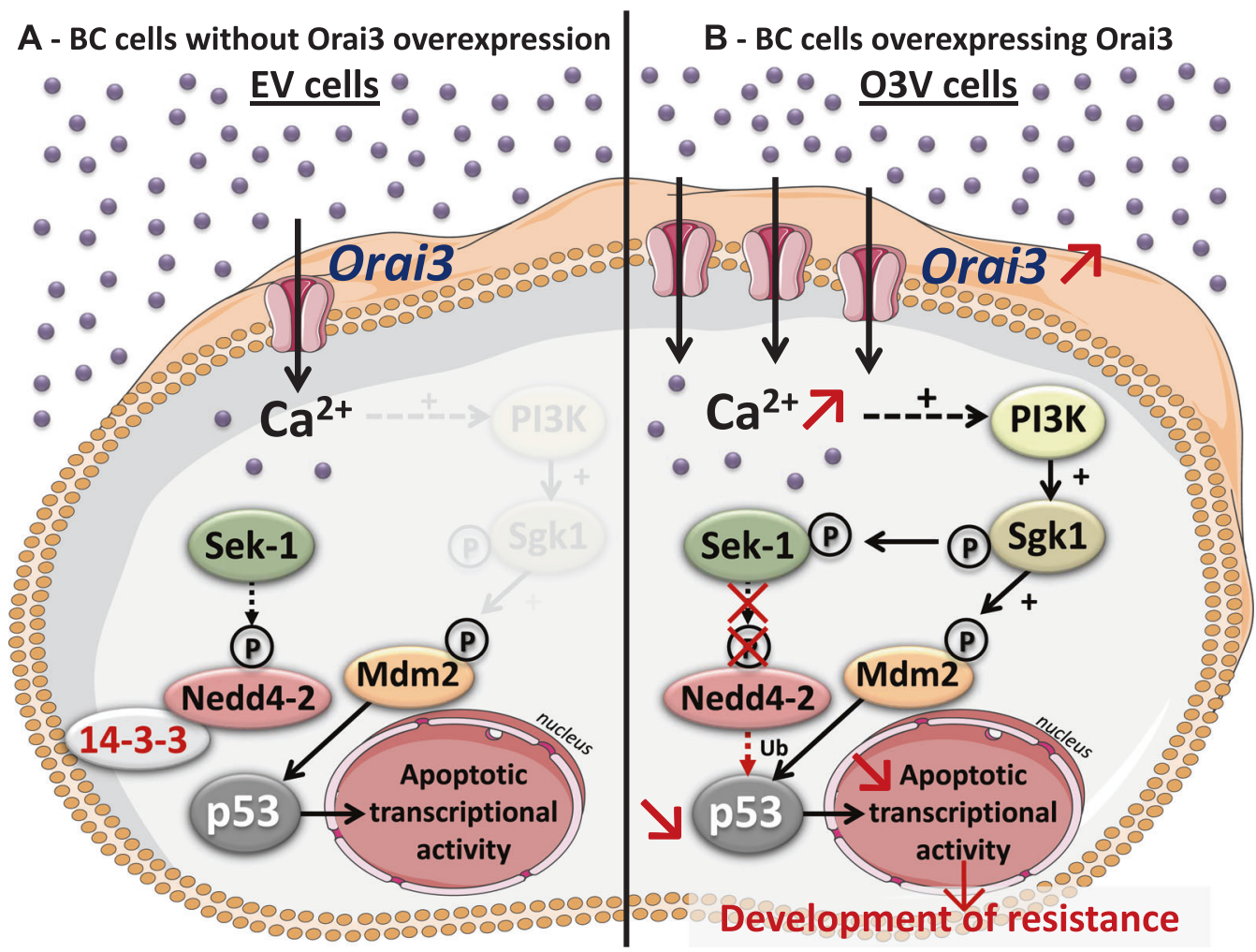

Fig. 7 Development of resistance in BC cells overexpressing Orai3. This scheme shows how Orai3 overexpression could contribute to the development of a resistant phenotype in $\mathrm{ER}^{+} \mathrm{BC}$ cells to cytotoxic and chemo-induced apoptosis. The mechanism of action involves p53 protein degradation via the PI3K/Sgk-1 signaling pathway and its downtream ubiquitin ligases: Mdm2, on one hand, and Nedd4-2, most probably via Sek-1, on the other hand. A In $\mathrm{ER}^{+} \mathrm{BC}$ empty vector (EV cells) cells, Orai3 mediates store-operated $\mathrm{Ca}^{2+}$ entry. PI3K/Sgk1 survival signaling pathway is not fully activated, Sek-1 (a target of Sgk-1) is not phosphorylated by Sgk-1, and is thus activated. Sek-1 can thus phosphorylate the ubiquitin ligase Nedd4-2, inducing its inactivation via its sequestration with the 14-3-3 protein. The tumor

Importantly, Orai3 overexpression was not only able to confer resistance to apoptosis in $\mathrm{ER}^{+}-\mathrm{BC}$ cells, but also in the non-tumoral Cos-7 cell line. This result, although quite unexpected, suggests that Orai 3 is apparently able to confer apoptosis resistance to virtually any other cell line.

SOCs have already been proposed as apoptosis regulators [10], and Orai3 would be one of them. External calcium was necessary for Orai3 to downregulate p53, and among all investigated pathways, we only found an implication of the PI3K. The fact that Orai3-conferred Aktindependent resistance was unexpected. Although Akt is considered to be one of the key enzymes driving resistance of cancer cells [34], PI3K is able to promote cancer by Aktindependent pathways, possibly by Sgk isoforms [35]. Sgk1 has been recently linked to resistance [36], is regulated by SOCE, and mediates cytoprotection against cell death in $\mathrm{ER}^{-} \mathrm{BC}$ cells [23]. Our data suggest that Orai3 was able to regulate Sgk-1 in $\mathrm{ER}^{+} \mathrm{BC}$ cells. It has been demonstrated suppressor protein p53 is expressed in EV cells, and can be activated upon stress signals inducing apoptotic death via its transcriptional activity. B In Orai3-overexpressing cells, $\mathrm{Ca}^{2+}$ entry is increased, activating PI3K/Sgk-1 survival signaling pathway. Sgk-1 (phosphorylated and activated by PI3K) phosphorylates and inactivates Sek1. Sek-1 is therefore unable to phosphorylate Nedd4-2, which is thus able to interact with its target proteins (including either p53 regulators or p53 directly), ubiquitinylating them and inducing their degradation. p53 is largely downregulated in O3V cells. p53 is still regulated by the ubiquitin ligase Mdm2 (phosphorylated by Sgk-1 activation, but downregulated following p53 decreased levels)

that Sgk-1 could activate Mdm2-dependent p53 degradation, thereby affecting cell proliferation, differentiation, and survival [26]. Since Sgk-1 phosphorylates ${ }^{166}$ Ser-Mdm2 [26], a higher phosphorylation level was expected in $\mathrm{O} 3 \mathrm{~V}$ cells. A higher $\mathrm{pMdm} 2 / \mathrm{Mdm} 2$ ratio was indeed found, most likely due to Sgk-1 activation, but a dramatic Mdm2 downregulation was evidenced (and this could be a consequence of the p53 downregulation in $\mathrm{O} 3 \mathrm{~V}$ cells, since $\mathrm{Mdm} 2$ is transcriptionally regulated by p53 [37]). It appeared thus difficult to consider Mdm2 as the sole p53 regulator in $\mathrm{O} 3 \mathrm{~V}$ cells (Mdm2 downregulation causes, on the contrary, an increase in p53 levels in T47D cells [38]). p53 was therefore likely degraded by another mechanism. Other ubiquitin ligases interacting with Sgk-1 are part of the Nedd4 E3 ubiquitin ligases family. Nedd4-1, known to ubiquitinylate tumor suppressors [39], was an ideal candidate but is not a target of Sgk-1 [40]. Nedd4-2, known to also ubiquitinylate ion channels and membrane transporters, can be 
phosphorylated by Sgk-1, and is also calcium-activated [39]. The fact that a partial Nedd4-2 downregulation was able to restore, at least partially, p53 protein levels indicated that Nedd4- 2 could also mediate p53 degradation, either in a direct or indirect way. Nedd4- 2 can be phosphorylated by Sgk-1 at 3 relevant phosphorylation sites, including a "major" site (Ser448, corresponding to Ser444 in Xenopus Laevis) regarding to 14-3-3 protein binding [41]. 14-3-3 proteins sequester pNedd4-2, reducing for instance its interaction with the sodium channel ENaC [42]. The ratio ${ }^{\text {Ser448 }}$ Nedd4-2/ Nedd4-2 was dramatically decreased, potentially implying a higher availability of Nedd4-2 for ubiquitination of target proteins (possibly including p53). However, Sgk-1, as a kinase, could not be implicated directly in Nedd4-2 dephosphorylation. We hypothesized that Sgk-1 was able to phosphorylate and inactivate a kinase targeting the Ser448 residue of Nedd4-2 (residue known to be phosphorylated by several kinases [43]). Sek-1, known to be inactivated by Sgk-1 [44], is part of the Sgk-1 signaling pathway leading to cell resistance [45], and is already described for regulating p53 expression [46]. Sek-1 protein content was indeed found to be phosphorylated and thus inactivated, and was also dramatically decreased in O3V cells. Sek-1 was thus a potential Nedd4-2 kinase. In good agreement with this hypothesis, Sek1 downregulation was able to decrease Nedd4-2 phosphorylation. This was likely to result in less Nedd4-2 sequestration with 14-3-3 proteins, and more Nedd4-2-mediated p53 degradation (confirmed at the protein level). Whether p53 can be ubiquitinated by Nedd4-2 requires further work. It is noteworthy that Nedd4-2 could also be directly activated by Orai3-mediated calcium entry (with calcium releasing autoinhibition of Nedd4-2 [39]). Further work is also needed to elucidate the Sgk-1/Sek-1/Nedd4-2/p53 relationships.

To summarize, we show here that the Orai3 calcium channel, overexpressed in most $\mathrm{ER}^{+}$breast tumors, is able to confer resistance to cell death by modulating $\mathrm{p} 53$ protein expression via the PI3K/Sgk-1 signaling pathway, which signals to activate the ubiquitin ligase Nedd4-2, most probably via Sek-1 (Fig. 7). We were able to show supporting evidence for our cell line experiments using real human BC patients using public data sets. Further work is needed to elucidate whether p53 degradation is directly or indirectly mediated by Nedd4-2, and to validate Orai3 as a predictive marker for cellular resistance against chemotherapeutic treatments in human breast tumors.

\section{Methods}

\section{Cell culture}

T47D and MCF7 BC cells were grown in Eagle's MEM supplemented with 5\% FCS (Fetal Calf Serum, Lonza), 2
mM glutamax, and $0.06 \%$ HEPES. Cos- 7 cells were grown in DMEM medium supplemented with $5 \%$ FCS and $2 \mathrm{mM}$ glutamax. All cell lines were grown in a $5 \% \mathrm{CO}_{2}$-humidified incubator at $37^{\circ} \mathrm{C}$.

\section{Plasmid constructs}

Orai3 gene was inserted into the pEF1 $\alpha$-IRES-DsRed plasmid. The plasmid allowed the generation of a bicistronic mRNA in transfected cells, with production of separate Orai3 and fluorescent DsRed proteins.

\section{Stable transfection}

Transfection was performed using the nucleofection technology (Amaxa), as previously described [47]. Cells were transfected either with pEF1 $\alpha$-IRES-DsRed vector as a control (referred in the text to as "EV"), or with $p E F 1 \alpha$ Orai3-IRES-DsRed (referred in the text to as "O3V," Orai3 vector).

\section{Selection of stable clones}

Transfected cells were selected for permanent integration of the plasmid in the genome with G418 (Sigma, $0.8 \mu \mathrm{g} \mathrm{ml}^{-1}$ ). Cells were sorted with a FACSCanto device (BecktonDickinson) 3 weeks after transfection. Each well of the 96well plates (three plates for $\mathrm{EV}$, three for $\mathrm{O} 3 \mathrm{~V}$ ) was then examined to rule out the presence of more than one clone per well. Two weeks after selection, a new selection was made based on relative fluorescence.

\section{Transient transfection}

Transfection was performed using the nucleofection technology according to the Amaxa Biosystems protocol. Cells were transfected with siSgk-1 (5'-GTGATCGGAAAGGGCAGTT-3', Eurogentec), a pool of siNedd4-2 (siNedd42\#1: 5'-AACCACAACACAAAGUCACAC-3'; siNedd42\#2: 5'- GUUGCUGGUCUGGCCGUAU - ${ }^{\prime}$, Eurogentec), siSek-1 (Santa Cruz \#sc-35909), or with control siRNA (duplex negative control, Eurogentec).

\section{Chemicals and reagents}

All chemicals were purchased from Sigma, unless otherwise stated. Clones were treated with cytotoxic and chemotherapeutic agents to induce cell mortality: $\operatorname{Tg}(1 \mu \mathrm{M}, 24 \mathrm{~h})$, STS $(1 \mu \mathrm{M}, 6 \mathrm{~h})$, cisplatin $(50 \mu \mathrm{M}, 24 \mathrm{~h}), 5$-FU $\left(40 \mu \mathrm{g} \mathrm{ml}^{-1}\right.$, $48 \mathrm{~h})$, paclitaxel $(100 \mathrm{nM}, 48 \mathrm{~h})$, etoposide $(40 \mu \mathrm{M}, 24 \mathrm{~h})$, and pemetrexed $(500 \mu \mathrm{M}, 24 \mathrm{~h})$. All these products were dissolved in DMSO (referred in the figures to as "no treatment," "nt"). Pharmacological inhibitors used to study the 
signaling pathways were the following: cyclosporine A (1

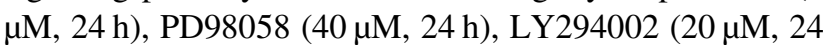
h), wortmannin $(200 \mathrm{nM}, 24 \mathrm{~h})$, PIK93 $(500 \mathrm{nM}, 24 \mathrm{~h})$, pifithrin- $\alpha(40 \mu \mathrm{M}, 24 \mathrm{~h})$, nutlin-3 $(20 \mu \mathrm{M}, 24 \mathrm{~h}), \mathrm{MG}-132$ $(5 \mu \mathrm{M}, 24 \mathrm{~h})$, calmidazolium chloride $(1 \mu \mathrm{M}, 24 \mathrm{~h})$, and GSK650394 (200 nM，24h). KN-93 $(1 \mu \mathrm{M} ， 24 \mathrm{~h})$ was purchased from RBI.

\section{Calcium imaging}

Cells were grown onto glass coverslips and were loaded for 45 min at $37^{\circ} \mathrm{C}$ with $3 \mu \mathrm{M}$ Fura-2/AM (Sigma). After Fura loading, cells were washed and kept in extracellular saline solution containing $145 \mathrm{mM} \mathrm{NaCl}, 5 \mathrm{mM} \mathrm{KCl}, 2 \mathrm{mM}$ $\mathrm{CaCl}_{2}, 1 \mathrm{mM} \mathrm{MgCl}_{2}, 5 \mathrm{mM}$ glucose, $10 \mathrm{mM}$ HEPES ( $\mathrm{pH}$ adjusted to 7.4 with $\mathrm{NaOH}$ ). The glass coverslip was mounted in a chamber on a Zeiss microscope equipped for fluorescence. Fura-2 fluorescence was excited at 340 and $380 \mathrm{~nm}$ using a monochromator (polychrome IV, TILL Photonics, Planegg, Germany), and captured by a Cool SNAPHQ camera (Princeton Instruments) after filtration through a long-pass filter $(510 \mathrm{~nm})$. Metafluor software (version 7.1.7.0, Molecular Devices) was used for acquisition and analysis. The $\left[\mathrm{Ca}^{2+}\right]_{\mathrm{i}}$ concentration was derived from the ratio of the fluorescence intensities for each of the excitations wavelengths $\left(F_{340} / F_{380}\right)$. The cells were continuously perfused with the saline solution. SOCE was monitored through $\mathrm{Tg}$-stimulated $\mathrm{Ca}^{2+}$ influx. We first perfused $1 \mu \mathrm{M} \mathrm{Tg}$ in $\mathrm{Ca}^{2+}$-free solution for $7 \mathrm{~min}$. Then, 2 $\mathrm{mM} \mathrm{Ca}{ }^{2+}$ was added.

\section{Real-time quantitative PCR (qRT-PCR)}

Extraction of total RNA from cell lines and real-time PCR were performed as previously described [14]. The relative amount of Orai3 mRNAs in BC cells were normalized to the endogenous control (ß-actin) using the Pfaffl method [48].

\section{Western blot analysis}

Whole-cell lysates were prepared with RIPA buffer containing a protease inhibitor cocktail (Sigma-Aldrich). The primary antibodies used were: anti-Orai3 (1:200, Sigma Prestige antibody), anti-Bcl-2 (1/500, Cell Signaling), antiBax (1/500, BD Pharmingen), anti-PARP (1/1000, Santa Cruz and 1/1000, AbCam), anti-p53 (1/1000, Santa Cruz), anti-Akt (1/1000, Cell signaling), anti-p-Akt (Ser473) (1/ 10,000, Cell signaling), anti-Sgk-1 and anti-p-Sgk-1-Ser422 (1/1000, AbCam), anti-Mdm2 (1/1000, AbCam), anti-pMdm2-Ser166 (1/1000, Santa Cruz), anti-Nedd4-2 and antip-Nedd4-2-Ser448 (1/1000, Abcam), and anti-Sek-1 and anti-p-Sek-1-Ser80 (1/1000, Abcam). Secondary antibodies were coupled to horseradish peroxidase. Actin antibody (1/ 2000, Santa Cruz Biotechnology) was used for loading control experiments. Bound antibodies were visualized using ECL chemiluminescent substrate (GE Healthcare) and quantified using the Bio-Rad image acquisition software (Quantity One).

\section{Dot-blot analysis}

The protein array "PathScan ${ }^{\circledR}$ stress and apoptosis signaling antibody array Kit" (Cell Signaling Technology) was analyzed with the plugin "Dot blot analyzer" for ImageJ (available at the Gilles Carpentier's Research website).

\section{Cell death and apoptosis}

Cell viability and mortality were first measured using Trypan Blue assay. BC cells were grown in $35 \mathrm{~mm}$ Petri dishes at a density of $1 \times 10^{5}$ cells for $72 \mathrm{~h}$. Cell count was assessed using the standard Malassez cell method. Cell counts were performed six times and the results were expressed as the percentage of viable or dead cells normalized to control. Cell death and apoptosis was also assessed with a biochemical method: cleaved PARP (AbCam), combined with anti-PARP-1 (Santa Cruz). Calcium-free solutions were made by addition of $150 \mu \mathrm{M}$ EGTA. In these conditions, free calcium is $<1 \mu \mathrm{M}$ [49].

\section{Bioinformatic analysis of public BC data sets}

ORAI3 DNA copy-number aberrations and mRNA overexpression compared to normal tissue (Fig. S1F, G, and H) was determined using Oncomine (https://www.oncomine. org/). The three data sets analyzed represent the largest DNA copy-number cohort, and the two largest mRNA expression profiling studies that contained samples for all major BC clinical subtypes. DNA copy-number gains and mRNA overexpression compared to normal tissue were calculated using $2 \log$ and $2 \log$ median-centered analyses, respectively. Statistical analyzes were according to default website settings.

For the correlation of tumor Orai 3 mRNA expression to therapy response in BC patients in Fig. 1, the public NCBI Gene Expression Omnibus (http://www.ncbi.nlm.nih.gov/ geo/) was browsed for breasts cancer cohorts with genomewide mRNA expression profiles as well as chemotherapy response annotation, resulting in three sets: Booser-508 (GSE25066), Quiles-61 (GSE28844), and Wessels-178 (GSE34138). Booser-508 and Quiles-61 are on Affymetrix HG U133, Wessels-178 on Illumina WG6v3 mRNA expression platforms. The three sets were uploaded and analyzed in R2: a genomics analysis and visualization platform developed in the Department of Oncogenomics at 
the Academic Medical Center-University of Amsterdam (http://r2.amc.nl). Expression data (CEL files) were analyzed as described previously [50]. Briefly, gene transcript levels were determined from data image files using GeneChip operating software (MAS5.0 and GCOS1.0, from Affymetrix). Samples were scaled by setting the average intensity of the middle $96 \%$ of all probe-set signals to a fixed value of 100 for every sample in the data set, allowing comparisons between microarrays. The TranscriptView genomic analysis and visualization tool within R2 was used to check if probe-sets uniquely mapped in an anti-sense orientation in a highly transcribed exon of the gene locus (http://r2.amc.nl > genome browser). The probe-sets selected for ORAI3 (Affymetrix 221864_at and Illumina 1736628) meet these criteria. All other details for the data sets, including their literature references, can be obtained through their GSE or E number from the NCBI GEO and EBI ArrayExpress websites, respectively. Orai3 mRNA expression correlation to therapy response was determined using the non-parametric Kruskal-Wallis test to prevent undue influence of non-normally distributed data.

The correlation of ORAI3 and TP53 DNA and mRNA aberrations in Fig. S4 was determined using the cBioPortal website (http://www.cbioportal.org/). Four data sets representing two independent studies, METABRIC and TCGA, had complete annotations for DNA mutation and copy number and mRNA expression, and were analyzed using a Fisher exact test according to default website settings.

All other details for the data sets, including their literature references, can be obtained through the cBioPortal, Oncomine, or R2 websites. All test results were considered statistically significant if $p<0.05$.

\section{Statistical analysis}

Values are expressed as mean \pm SEM. Statistical analysis of the data was performed using appropriate analysis of variance, Mann-Whitney or $t$ tests. Differences were considered significant at $p<0.05$ unless otherwise stated.

Acknowledgements This study was supported by Région Picardie, le Ministère de l'Education Nationale (France), and la Ligue Nationale Contre le Cancer (SEPTENTRION).

Author contributions H.O.-A., P.K., D.G., F.H., D.T., and J.H. designed the experiments. J.H., P.K., D.G., L.R.-D., F.H., and C.L. performed and analyzed the experiments. All authors discussed the results and commented on the manuscript. P.K., J.H., D.G., and H.O.A. wrote the manuscript.

\section{Compliance with ethical standards}

Conflict of interest The authors declare that they have no competing interests.

\section{References}

1. Gonzalez-Angulo AM, Morales-Vasquez F, Hortobagyi GN. Overview of resistance to systemic therapy in patients with breast cancer. Adv Exp Med Biol. 2007;608:1-22.

2. Li S, Kennedy M, Payne S, Kennedy K, Seewaldt VL, Pizzo SV, et al. Model of tumor dormancy/recurrence after short-term chemotherapy. PLoS ONE. 2014;9:e98021.

3. Prevarskaya N, Skryma R, Shuba Y. Ion channels and the hallmarks of cancer. Trends Mol Med. 2010;16:107-21.

4. D’Amico M, Gasparoli L, Arcangeli A. Potassium channels: novel emerging biomarkers and targets for therapy in cancer. Recent Pat Anticancer Drug Discov. 2013;8:53-65.

5. Berridge MJ, Lipp P, Bootman MD. The versatility and universality of calcium signalling. Nat Rev Mol Cell Biol. 2000;1:11-21.

6. Monteith GR, McAndrew D, Faddy HM, Roberts-Thomson SJ. Calcium and cancer: targeting $\mathrm{Ca} 2+$ transport. Nat Rev Cancer. 2007;7:519-30.

7. Berridge MJ, Bootman MD, Lipp P. Calcium - a life and death signal. Nature. 1998;395:645-8.

8. Putney JW. Capacitative calcium entry: from concept to molecules. Immunol Rev. 2009;231:10-22.

9. Flourakis M, Lehen'kyi V, Beck B, Raphael M, Vandenberghe M, Abeele FV, et al. Orail contributes to the establishment of an apoptosis-resistant phenotype in prostate cancer cells. Cell Death Dis. 2010;1:e75.

10. Abeele FV, Skryma R, Shuba Y, Van Coppenolle F, Slomianny $\mathrm{C}$, Roudbaraki M, et al. Bcl-2-dependent modulation of $\mathrm{Ca} 2+$ homeostasis and store-operated channels in prostate cancer cells. Cancer Cell. 2002;1:169-79.

11. Orrenius S, Zhivotovsky B, Nicotera P. Regulation of cell death: the calcium-apoptosis link. Nat Rev Mol Cell Biol. 2003;4:552-65.

12. Shuttleworth TJ. Orai3-the 'exceptional' Orai? J Physiol. 2012;590:241-57.

13. Schindl R, Bergsmann J, Frischauf I, Derler I, Fahrner M, Muik $\mathrm{M}$, et al. 2-Aminoethoxydiphenyl borate alters selectivity of Orai3 channels by increasing their pore size. J Biol Chem. 2008;283:20261-7.

14. Faouzi M, Hague F, Potier M, Ahidouch A, Sevestre H, OuadidAhidouch $\mathrm{H}$, et al. Down-regulation of Orai3 arrests cell-cycle progression and induces apoptosis in breast cancer cells but not in normal breast epithelial cells. J Cell Physiol. 2011;226: 542-51.

15. Faouzi M, Kischel P, Hague F, Ahidouch A, Benzerdjeb N, Sevestre $\mathrm{H}$, et al. ORAI3 silencing alters cell proliferation and cell cycle progression via c-myc pathway in breast cancer cells. Biochim Biophys Acta. 2013;1833:752-60.

16. Motiani RK, Abdullaev IF, Trebak M. A novel native storeoperated calcium channel encoded by Orai3: selective requirement of Orai3 versus Orai1 in estrogen receptor-positive versus estrogen receptor-negative breast cancer cells. J Biol Chem. 2010;285:19173-83.

17. Lis A, Peinelt C, Beck A, Parvez S, Monteilh-Zoller M, Fleig A, et al. CRACM1, CRACM2, and CRACM3 are store-operated Ca2 + channels with distinct functional properties. Curr Biol. 2007; 17:794-800.

18. Oltval ZN, Milliman CL, Korsmeyer SJ. Bcl-2 heterodimerizes in vivo with a conserved homolog, Bax, that accelerates programed cell death. Cell. 1993;74:609-19.

19. Basu A, Haldar S. The relationship between BcI2, Bax and p53: consequences for cell cycle progression and cell death. Mol Hum Reprod. 1998;4:1099-109. 
20. Mooney LM, Al-Sakkaf KA, Brown BL, Dobson PRM. Apoptotic mechanisms in T47D and MCF-7 human breast cancer cells. Br J Cancer. 2002;87:909-17.

21. Toledo F. Role of TP53 mutations in cancer (an overview). In: Hayat MA, editor. General methods and overviews, lung carcinoma and prostate carcinoma, vol. 2. Netherlands: Springer; 2008. p. 75-92.

22. Lukashchuk N, Vousden KH, Ubiquitination and degradation of mutant p53. Mol Cell Biol. 2007;27:8284-95

23. Brickley DR, Agyeman AS, Kopp RF, Hall BA, Harbeck MC, Belova L, et al. Serum- and glucocorticoid-induced protein kinase 1 (SGK1) is regulated by store-operated $\mathrm{Ca} 2+$ entry and mediates cytoprotection against necrotic cell death. J Biol Chem. 2013;288:32708-19.

24. Kobayashi T, Cohen P. Activation of serum- and glucocorticoidregulated protein kinase by agonists that activate phosphatidylinositide 3-kinase is mediated by 3-phosphoinositide-dependent protein kinase-1 (PDK1) and PDK2. Biochem J. 1999;339:319-28.

25. Sherk AB, Frigo DE, Schnackenberg CG, Bray JD, Laping NJ, Trizna W, et al. Development of a small-molecule serum- and glucocorticoid-regulated kinase-1 antagonist and its evaluation as a prostate cancer therapeutic. Cancer Res. 2008;68:7475-83.

26. Amato R, D'Antona L, Porciatti G, Agosti V, Menniti M, Rinaldo C, et al. Sgk1 activates MDM2-dependent p53 degradation and affects cell proliferation, survival, and differentiation. J Mol Med. 2009;87:1221-39.

27. Bhalla V, Daidié D, Li H, Pao AC, LaGrange LP, Wang J, et al. Serum- and glucocorticoid-regulated kinase 1 regulates ubiquitin ligase neural precursor cell-expressed, developmentally downregulated protein 4-2 by inducing interaction with 14-3-3. Mol Endocrinol. 2005;19:3073-84.

28. Nguyen DX, Bos PD, Massague J. Metastasis: from dissemination to organ-specific colonization. Nat Rev Cancer. 2009;9:274-84.

29. Prevarskaya N, Skryma R, Shuba Y. Ca2+ homeostasis in apoptotic resistance of prostate cancer cells. Biochem Biophys Res Commun. 2004;322:1326-35.

30. Dubois C, Vanden Abeele F, Lehen'kyi V, Gkika D, Guarmit B, Lepage $\mathrm{G}$, et al. Remodeling of channel-forming ORAI proteins determines an oncogenic switch in prostate cancer. Cancer Cell. 2014; 26:19-32.

31. Igney FH, Krammer PH. Death and anti-death: tumour resistance to apoptosis. Nat Rev Cancer. 2002;2:277-88.

32. Giorgi C, Bonora M, Sorrentino G, Missiroli S, Poletti F, Suski $\mathrm{JM}$, et al. p53 at the endoplasmic reticulum regulates apoptosis in a Ca2+-dependent manner. Proc Natl Acad Sci USA. 2015;112:1779-84.

33. Wu Y, Mehew JW, Heckman CA, Arcinas M, Boxer LM. Negative regulation of bcl-2 expression by p53 in hematopoietic cells. Oncogene. 2001;20:240-51.

34. Burris H III. Overcoming acquired resistance to anticancer therapy: focus on the PI3K/AKT/mTOR pathway. Cancer Chemother Pharmacol. 2013;71:829-42.

35. Vasudevan KM, Barbie DA, Davies MA, Rabinovsky R, McNear CJ, Kim JJ, et al. AKT-independent signaling downstream of oncogenic PIK3CA mutations in human cancer. Cancer Cell. 2009;16:21-32.

36. Sommer EM, Dry H, Cross D, Guichard S, Davies BR, Alessi DR, et al. Elevated SGK1 predicts resistance of breast cancer cells to Akt inhibitors. Biochem J. 2013;452:499-508.
37. Zhao $\mathrm{Y}, \mathrm{Yu} \mathrm{H}, \mathrm{Hu}$ W. The regulation of MDM 2 oncogene and its impact on human cancers. Acta Biochim Biophys Sin (Shanghai). 2014;46:180-9.

38. Zheng T, Wang J, Zhao Y, Zhang C, Lin M, Wang X, et al. Spliced MDM2 isoforms promote mutant p53 accumulation and gain-of-function in tumorigenesis. Nat Commun. 2013;4:2996

39. Wang J, Peng Q, Lin Q, Childress C, Carey D, Yang W, et al. Calcium activates Nedd4 E3 ubiquitin ligases by releasing the $\mathrm{C} 2$ domain-mediated auto-inhibition. J Biol Chem. 2010;285:12279-88.

40. Snyder PM, Olson DR, Thomas BC. Serum and glucocorticoidregulated kinase modulates Nedd4-2-mediated inhibition of the epithelial Na+ channel. J Biol Chem. 2002;277:5-8.

41. Chandran S, Li H, Dong W, Krasinska K, Adams C, Alexandrova $\mathrm{L}$, et al. Neural precursor cell-expressed developmentally downregulated protein 4-2 (Nedd4-2) regulation by 14-3-3 protein binding at canonical serum and glucocorticoid kinase 1 (SGK1) phosphorylation sites. J Biol Chem. 2011;286:37830-40.

42. Wiemuth D, Lott JS, Ly K, Ke Y, Teesdale-Spittle P, Snyder PM, et al. Interaction of serum- and glucocorticoid regulated kinase 1 (SGK1) with the WW-domains of Nedd4-2 is required for epithelial sodium channel regulation. PLoS ONE. 2010;5: e12163.

43. Snyder PM, Down-regulating destruction: phosphorylation regulates the E3 ubiquitin ligase Nedd4-2. Sci Signal. 2009;2:pe41

44. Kim MJ, Chae JS, Kim KJ, Hwang SG, Yoon KW, Kim EK, et al. Negative regulation of SEK1 signaling by serum- and glucocorticoid-inducible protein kinase 1. EMBO J. 2007;26: 3075-85.

45. Iqbal S, Howard S, LoGrasso PV. Serum- and glucocorticoidinducible kinase 1 confers protection in cell-based and in in vivo neurotoxin models via the c-Jun N-terminal kinase signaling pathway. Mol Cell Biol. 2015;35:1992-2006.

46. Hawkes WC, Alkan Z. Delayed cell cycle progression in selenoprotein W-depleted cells is regulated by a mitogen-activated protein kinase kinase 4-p38/c-Jun NH2-terminal kinase-p53 pathway. J Biol Chem. 2012;287:27371-9.

47. Borowiec AS, Hague F, Harir N, Guenin S, Guerineau F, Gouilleux F, et al. IGF-1 activates hEAG $\mathrm{K}(+)$ channels through an Akt-dependent signaling pathway in breast cancer cells: role in cell proliferation. J Cell Physiol. 2007;212:690-701.

48. Pfaffl MW. A new mathematical model for relative quantification in real-time RT-PCR. Nucleic Acids Res. 2001;29:e45.

49. Borowiec A-S, Bidaux G, Tacine R, Dubar P, Pigat N, Delcourt P, et al. Are Orai1 and Orai3 channels more important than calcium influx for cell proliferation? Biochim Biophys Acta. 2014;1843:464-72.

50. Revet I, Huizenga G, Chan A, Koster J, Volckmann R, van Sluis $\mathrm{P}$, et al. The MSX1 homeobox transcription factor is a downstream target of PHOX2B and activates the Delta-Notch pathway in neuroblastoma. Exp Cell Res. 2008;314:707-19.

51. Ogston KN, Miller ID, Payne S, Hutcheon AW, Sarkar TK, Smith I, et al. A new histological grading system to assess response of breast cancers to primary chemotherapy: prognostic significance and survival. Breast. 2003;12:320-7.

52. Tabchy A, Valero V, Vidaurre T, Lluch A, Gomez H, Martin M, et al. Evaluation of a 30-gene paclitaxel, fluorouracil, doxorubicin, and cyclophosphamide chemotherapy response predictor in a multicenter randomized trial in breast cancer. Clin Cancer Res. 2010;16:5351-61. 